\title{
A Giant Oral Lipoma with Possible Post-Traumatic Origin: A Rare Entity at the University Teaching Hospital Center of Yaounde
}

\author{
David Bienvenue Ntep Ntep ${ }^{1}$, Charles Bengondo ${ }^{1}$, Ernest Kenna ${ }^{2}$, Coralie Mendouga Menye ${ }^{3}$
}

${ }^{1}$ Department of Odontostomatology and Maxillofacial Surgery, Yaounde University, Teaching and Hospital Center, Cameroon,

${ }^{2}$ Limbe Regional Hospital, Cameroon, ${ }^{3}$ Pasteur Center of Yaoundé, Cameroon

\begin{abstract}
Lipomas are benign tumors of adipose tissue with pathogenesis and a controversial etiology. An explicit link between soft tissue trauma and the occurrence of lipomas is difficult to establish. However, some cases have been described. These soft tissue tumors have been called "post-traumatic lipomas". Clinically oral lipomas appear as yellowish nodular masses less than $3 \mathrm{~cm}$ in diameter. Yet the oral lipoma can increase in size from 5 to $11 \mathrm{~cm}$ over several years. The reported case is the first referred in our service. It was a mass located on the inside of the left cheek painless, nodular, yellowish about $8 \mathrm{~cm}$ in diameter, secondary to trauma. The treatment was surgical under local anesthesia. In the presence of mature fat cells very similar in appearance to the surrounding normal fat associated with a detachment of the superficial layers of the oral epithelium, the suggested diagnosis was a posttraumatic intraoral lipoma.
\end{abstract}

Key Words: Lipoma, Adipose, Trauma, Mesenchymal tumors

\section{Introduction}

Lipomas are mesenchymal tumors composed of mature adipocytes without cell abnormalities [1]. It is the most common benign soft tissue tumor. Compared to other areas of the body, they are quite rare in the oral cavity $[2,3]$. These are usually slow-growing, soft, and asymptomatic masses [4,5]. Most lipomas are less than $3 \mathrm{~cm}$ in size, but once present in the oral cavity, this tumor can increase from 5 to $11 \mathrm{~cm}$ for several years [6].

The etiology and pathogenesis are still unknown. It occurs more frequently in obese patients. Post-traumatic lipomas are tumors of adipose tissue forming at the site of a previous trauma occurring between 5 months and 6 years after the trauma [7].

We report the clinical, histopathological and etiopathogenical characteristic of a large post-traumatic lipoma of the oral mucosa.

\section{Case Presentation}

In March 2018, Mr. AG aged 41 years was sent to the dentistry and maxillofacial surgery department of the University Teaching hospital of Yaoundé, for the treatment of an intraoral swelling.

The patient described the onset of an oral swelling four years ago. This swelling increased in volume, impeding phonation and chewing, what motivated his consultation.

The general condition, medical history was unremarkable. Nevertheless, the patient mentioned the appearance of an ipsilateral jaw wound about 6 years ago following an instrumental trauma during a tooth extraction.

At the extraoral examination, there was swelling, extending from the left labial commissure to the upper genital region. The overlying skin was normal. The swelling was soft, painless on palpation. Cervicofacial lymphadenopathies were non-palpable.
Intraoral examination revealed nodular swelling, sometimes protruding beyond the oral cavity, impeding speech. The mass had a diameter of $8 \mathrm{~cm}$, pedicled with well-defined borders, regular outline and resilient consistency in some places. The mucosa covering the swelling showed a rich vascularization but also irregular whitish areas probably associated with trauma as shown in Figure 1.

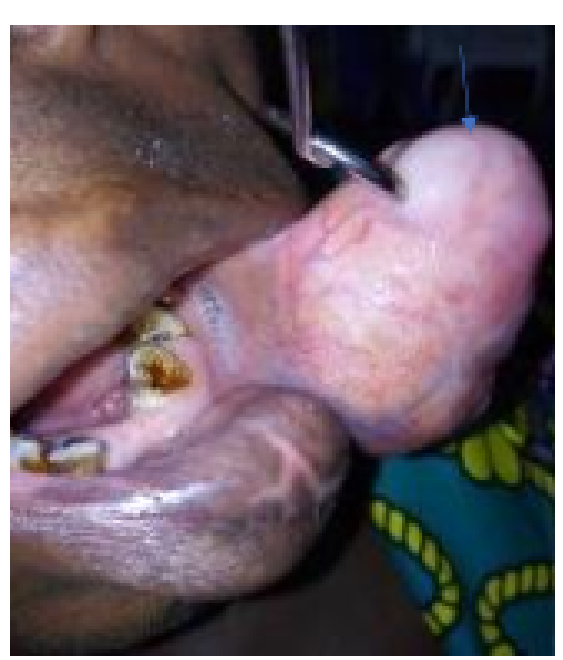

Figure 1. Submucosal swelling of the inner face of the left cheek.

The suggested diagnostic for this clinical picture were: lipoma, pseudolipoma, buccal hernia, and pleomorphic adenoma of the accessory salivary glands.

We excised the lesion from the buccinator muscle under local anesthesia and sutured the wound with $2 \%$ vicryl catgut.

The sutured wound was managed with polyvidone iodine and antibiotic therapy (amoxicillin) for seven days. There was no postoperative complaint.

Macroscopic examination revealed an irregularly shaped tissue of $8.3 \times 8.1 \times 6.6 \mathrm{~cm}$, yellow in color, soft in 
consistency with irregular edges and a rough surface, as shown in Figure 2.

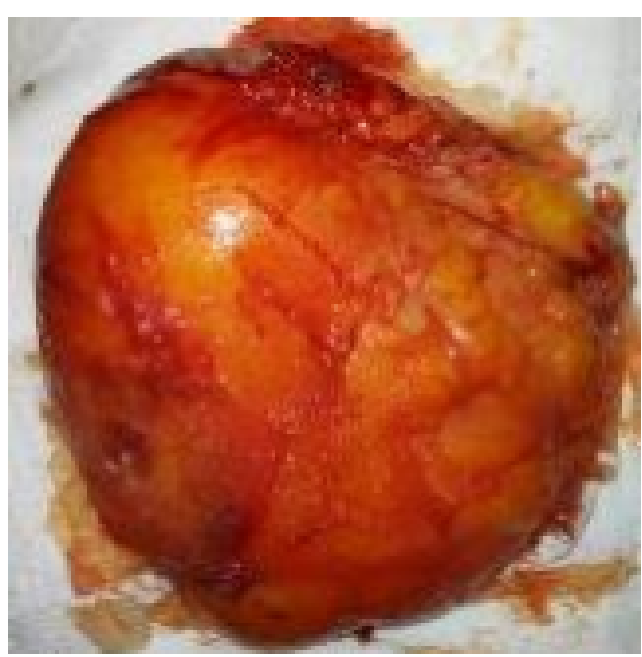

Figure 2. Macroscopic appearance of swelling after resection.

Histopathological examination showed a distinct lobular pattern composed of mature adipocytes partitioned by dense connective tissue (Figure 3).

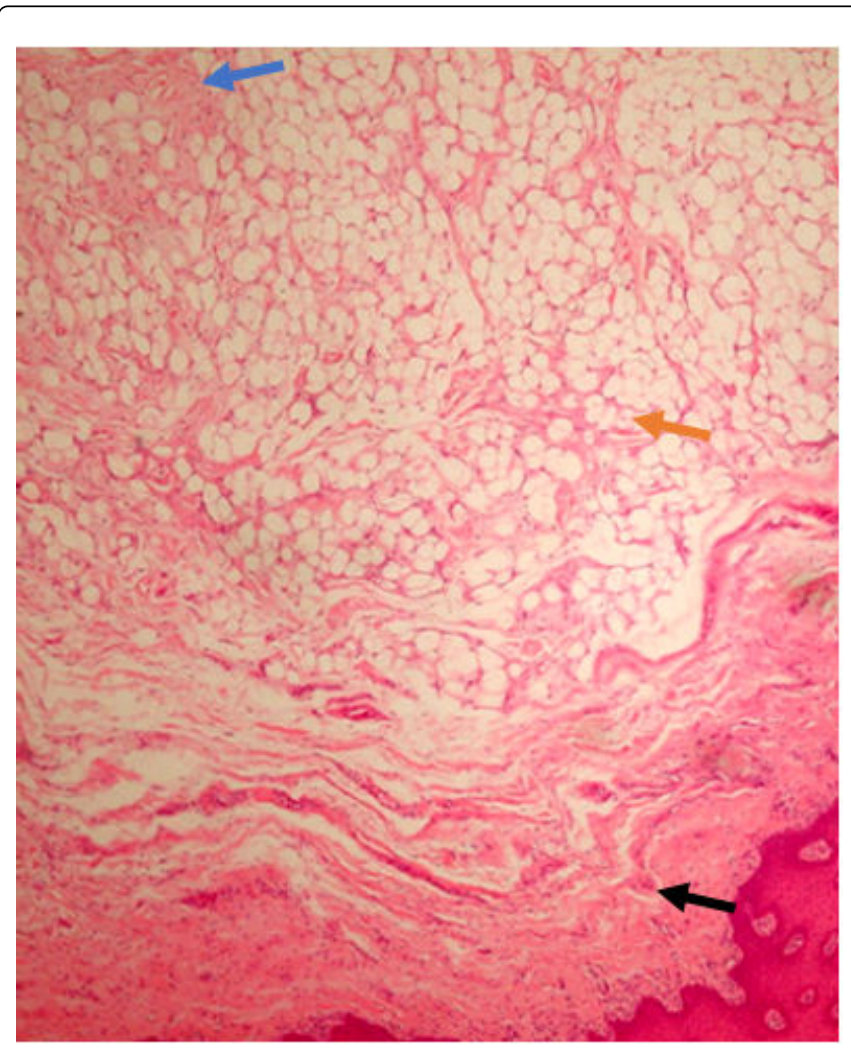

Figure 3. Microscopic characteristics: mature adipocytes clusters separated by dense connective tissue (blue arrow: dense connective tissue; black arrow: adipocytes, red arrow: epithelial detachment).

The oral mucosa consisted of stratified squamous epithelium with both ortho and parakeratotic layers with peeling of the surface layers. According to the histopathological characteristics, the diagnosis of a posttraumatic fibro lipoma was retained.
During a post-surgical follow-up of 26 months, no recurrence or complication was observed.

\section{Discussion}

Oral lipoma accounts for less than about $5 \%$ of all benign oral tumors [8]. The most common place for their appearance is the oral mucosa. The case presented here fits this location.

Most lipomas have a maximum dimension of less than $3 \mathrm{~cm}$ at the time of diagnosis. However, an oral lipoma can increase from 5 to $11 \mathrm{~cm}$ over several years [6], as was the case in our description. Their consistency can be firm or elastic, depending on the amount of connective tissue they harbor. Their yellow color (often egg yolk) is sometimes visible through the mucosa when it is tight [9].

Although no aetiological factor or predisposing to the occurrence of oral lipomas was found, we had evoked a traumatic origin. However, if trauma was a relevant factor, lipomas would be likely to occur more frequently, given the frequency of trauma.

The pathogenetic link between soft tissue trauma and posttraumatic lipoma formation is still controversial. There are two possible explanations for correlating soft tissue trauma and the growth of adipose tissue tumors $[7,10]$.

The first is the formation of post-traumatic pseudolipoma by fascial adipose tissue prolapsus resulting from a direct impact $[7,10]$. After a previous trauma causing the release of pro-inflammatory factors and of free adipocytes, it follows a progressive growth of a large tumor, called pseudolipoma. This entity then forms a capsule and becomes a lipoma. This process is probably immediately after the trauma and does not seem close to the case described.

The second theory is based on the effect of cytokines and growth factors released by platelets, macrophages, and fibroblasts in a hematoma and local inflammation after soft tissue trauma. These effects can lead to the differentiation of preadipocytes into mature adipocytes forming new adipose tissue $[7,10]$. This process seems to be slow and would correspond to the case presented.

Microscopic analysis of the case presented also confirms a history of trauma as so far as it revealed a zone compatible with the Morsicatio buccarum [11]. Indeed, the oral mucosa is frequently traumatized and the possible role of trauma in the growth of the oral lipoma cannot be ruled out.

\section{Conclusion}

Lipoma is a benign tumor of fat cells whose pathogenesis is controversial. When we talk about trauma among these etiologies, the controversy does not end. The diagnosis of post-traumatic oral lipoma can be made before, a jugular mass of dimension greater than or equal to $3 \mathrm{~cm}$, nodular, painless, pediculate, occurring long after the trauma.

Histology shows a distinct lobular pattern composed of mature adipocytes associated with detached, ortho and paraperatotic oral epithelium. The treatment is surgical. 


\section{References}

1. Mary A. Furlong, Julie C. Fanburg-Smith, Esther LB Childers. Lipoma of the oral and maxillofacial region: Site and sub classification of 125 cases. Oral Surgery, Oral Medicine, Oral Pathology. 2004; 98: 10.

2. Bandéca MC, de Pádua JM, Nadalin MR, Ozório JE, SilvaSousa YT, et al. Oral soft tissue lipomas: a case series. Journal of the Canadian Dental Association. 2007; 73: 431-434.

3. Raj AA, Shetty PM, Yadav SK. Lipome du plancher de la bouche: rapport d'une lesion inhabituellement importante. Journal of Maxillofacial and Oral Surgery. $2014 ; \mathbf{1 3}$.

4. Fletcher CDM, Unni KK, Mertens F. Classification de l'organisation mondiale de la santé des tumeurs. pathologie et génétique : Tumeurs des tissus mous et des os. IARC Press, tumeurs adipocytaires. 2002: 9-46.

5. Hoseini AT, Razavi SM, Khabazian A. Lipoma in oral mucosa: two case reports. Journal of Dental Research. 2010; 7: 41-43.

6. Egido Moreno S, Lozano Porras AB, Mishra S, Allegue Allegue M, Marí Roig A, et al. Intraoral lipomas: Review of literature and report of two clinical cases. Journal of Clinical and Experimental Dentistry. 2016; 8: 597-603.

7. Aust MC, Spies M, Kall S, Gohritz A, Boorboor P, et al. Lipomas after blunt soft tissue trauma: are they real? Analysis of 31 cases. British Journal of Dermatology. 2007; 157: 92-99.

8. Fregnani ER, Pires FR, Falzoni R, Lopes MA, Vargas PA. Lipomas of the oral cavity: clinical findings, histological classification and proliferative activity of 46 cases. International Journal of Oral and Maxillofacial Surgery. 2003; 32: 49-53.

9. Taira Y, Yasukawa K, Yamamori I, Iino M. Oral lipoma extending superiorly from mandibular gingivobuccal fold to gingiva: a case report and analysis of 207 patients with oral lipoma in Japan. Odontology. 2012; 100: 104-108.

10. Aust MC, Spies M, Kall S, Jokuszies A, Gohritz A, et al. Posttraumatic lipoma: fact or fiction? Skinmed. 2007; 6: 266-270.

11. Ponce JB, Ferreira GZ, Santos PS da S, Lara VS. Giant oral lipoma: A rare entity. Anais Brasileiros De Dermatologia. 2016; 91: 84-86. 